\title{
CONJUNTURA DE FATORES E RESPONSABILIDADES DOS CASOS DE POLUIÇÃO DA PRAIA DE CANASVIEIRAS- FLORIANÓPOLIS/SC
}

\author{
Elivelton Grisa $^{(\mathrm{a})}$, Edna Lindaura Luiz ${ }^{(\mathrm{b})}$ \\ (a) Licenciado em Geografia, Universidade do Estado de Santa Catarina (UDESC), elivelton2g@ gmail.com \\ (b) Profa. Dra. Departamento Geografia, Universidade do Estado de Santa Catarina (UDESC), elinluiz@uol.com.br
}

\section{Eixo: DINÂMICA E GESTÃO DE ZONAS COSTEIRAS}

\begin{abstract}
Resumo
O presente trabalho trata dos casos de poluição da praia de Canasvieiras em Florianópolis/SC, procurando discutir suas causas. O rio do Brás que deságua na praia é o responsável pela poluição dela. $\mathrm{O}$ rio recebe esgotos domésticos vindos da rede pluvial e do mau funcionamento de uma estação elevatória de esgoto. Obras estão sendo realizadas para melhorar a rede de coleta e tratamento de esgotos, porém é necessário conscientizar a população local para realizar as ligações na rede de esgoto e não sobrecarregá-la com gordura e águas pluviais.
\end{abstract}

Palavras chave: Sitema de esgotos, Baneabilidade de praia; Poluição do rio Brás-Fpolis/SC.

\section{Introdução}

A praia de Canasvieiras, em Florianópolis/SC, é uma das mais procuradas nas temporadas de verão, pois apresenta águas calmas e mais quentes, entretanto, muitas vezes, não há condições de balneabilidade. Um pequeno rio que deságua nesta praia, o rio do Brás, é responsabilizado pelos casos de poluição. O rio do Brás não possui vazão significativa e geralmente apresenta sua foz na praia fechada por uma barra arenosa criada pela deposição de correntes marinhas. Suas águas ficam represadas e recebem uma grande carga de esgotos domésticos e comerciais. Nos episódios de chuvas intensas, o rio do Brás aumenta sua vazão e destrói a barreira arenosa, alcançando o mar. Nestes momentos, uma carga de poluentes se espalha pela areia da praia e pelo mar adjacente, provocando problemas de saúde nos banhistas e prejuízos econômicos para o bairro (GONÇALVES, 2016).

O bairro Canasvieiras, onde está a praia, é altamente urbanizado e com muitos hotéis, pousadas, bares e restaurantes, lojas, ou seja, tem sua estrutura e funcionamento voltados para o turismo de veraneio. Não há dados precisos, mas há relatos de que sua população mais que duplica nos meses de verão. Tudo isso leva a uma grande produção de esgotos, especialmente nos meses de temporada, embora o norte do município de Florianópolis, onde o bairro se encontra, é a região mais populosa. 
Os bairros de Canasvieiras, Cachoeira do Bom Jesus, Ponta das Canas e parte do bairro Ingleses, na região norte de Florianópolis, contam com rede de coleta e estação de tratamento de esgotos da Companhia Catarinense de Águas e Saneamento (CASAN), o "Sistema Rio do Brás". Alguns elementos da estrutura de coleta e tratamento de esgotos se encontram junto do curso do rio do Brás, como: um tronco coletor de esgotos, uma estação elevatória de esgotos e a própria estação de tratamento dos esgotos (ETE). Por isso, grande parte da população local culpa a CASAN pela poluição no rio do Brás. Contudo, faz-se necessária uma análise mais profunda das causas da poluição do rio do Brás, que leva a poluição da praia de Canasvieiras quando ele rompe a barreira arenosa que fecha sua foz. Desta forma, o objetivo do presente trabalho é analisar as situações que provocaram os episódios de poluição da praia de Canasvieiras em Florianópolis/SC no período 2000-2016, bem como identificar as responsabilidades pelo fenômeno de poluição da praia. Os resultados do presente estudo pretendem subsidiar propostas de medidas que minimizem ou resolvam os casos de poluição da praia de Canasvieiras.

\section{Localização e delimitação da área de estudo.}

A área de estudo compreende dois recortes: um deles abrange toda a região servida pela rede de coleta e tratamento de esgotos do "Sistema Rio do Brás" que contém os bairros: de Canasvieiras, Cachoeira do Bom Jesus, Ponta das Canas e parte do bairro Ingleses, na região norte de Florianópolis, e o outro a bacia do rio do Brás e a praia de Canasvieiras. Figuras 1 e 2.

\section{Materiais e métodos}

O trabalho foi realizado a partir de pesquisa em reportagens de jornais, conversas informais com moradores do bairro Canasvieiras e entrevistas com técnicos da CASAN. Também foram realizadas visitas a ETE do rio do Brás e vistorias in loco ao longo do canal do rio do Brás e nas estruturas da rede coletora que estão na superfície. Além disso, foi utilizado o conhecimento de vivência no local de um dos autores do presente trabalho, que morou e trabalhou no bairro Canasvieiras nos últimos anos. As informações obtidas nas conversas e entrevistas e nas reportagens subsidiaram a análise de conjuntura de cada caso de poluição identificado no período 2000 a 2016. As visitas a campo permitiram confirmar informações e acompanhar o funcionamento e os problemas do sistema de esgotos "Rio do Brás". A coleta e a sistematização das informações mostraram mais claramente cada situação geradora de poluição da praia em cada episódio e a atribuição de responsabilidades em cada um deles. 


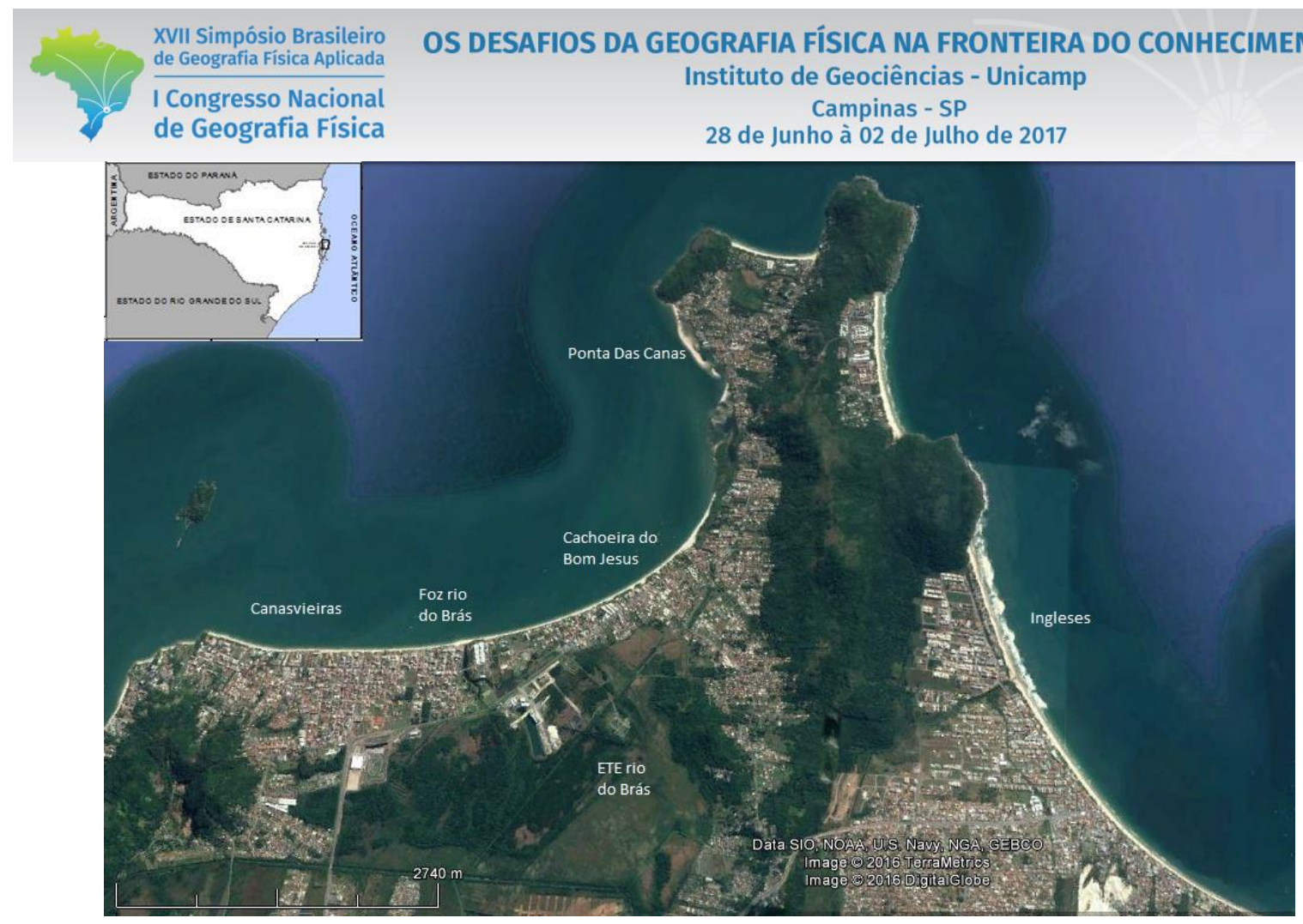

Figura 1- Localização da área de estudo.

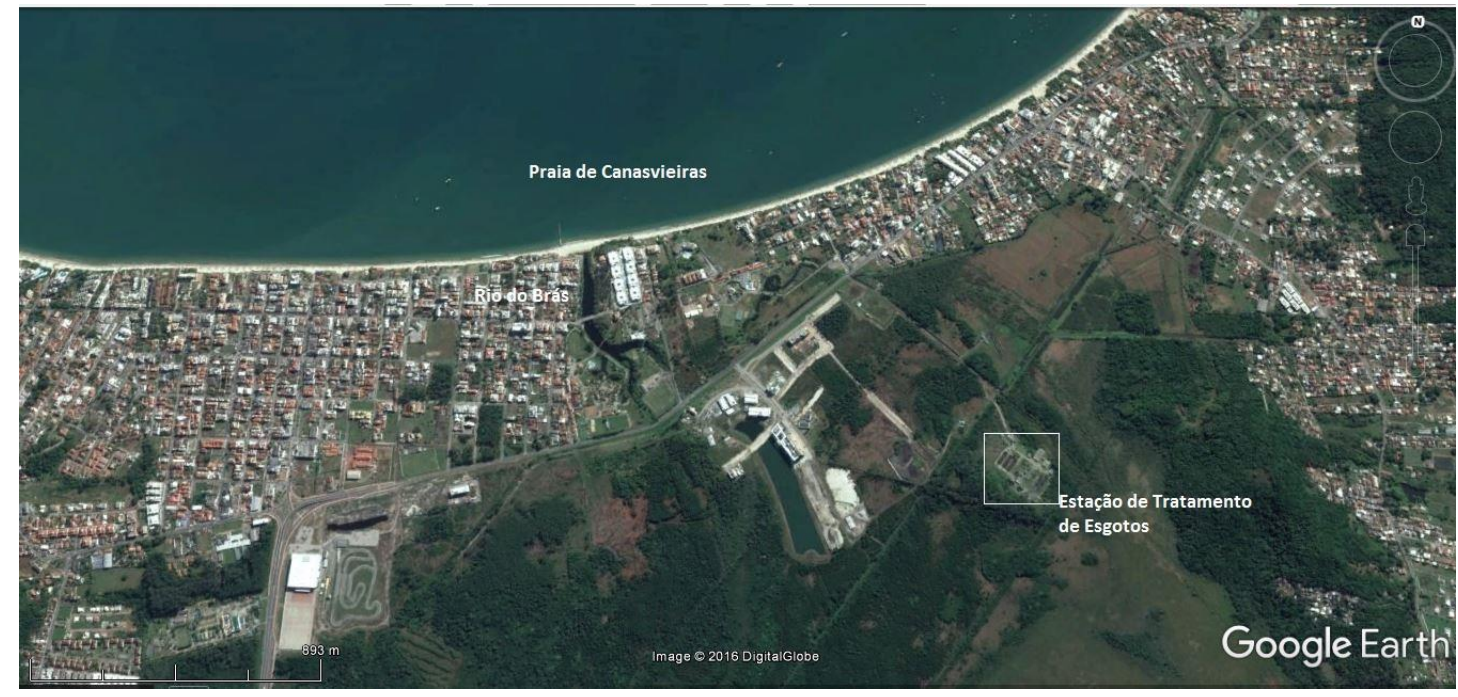

Figura 2 - Detalhe da Figura 1: foz fechada por barreira arenosa.

\section{Resultados}

A rede coletora do "Sistema do Rio do Brás" é composta das seguintes estruturas: canalizações individuais ou coletivas (prédios), Coletores prediais (domésticos ou comerciais), Coletores-tronco, Interceptores, Estação elevatória, Emissários. O que foi encontrado a partir de entrevistas com os moradores locais e com os técnicos da CASAN e ainda observações in loco é que muitos moradores têm irregularidades em 
suas canalizações individuais, tais como: falta de caixa de gordura, ligação do escoamento de água pluvial do imóvel dentro da canalização do esgoto e caixas de passagem precárias.,. Algumas vezes, na rede coletora de esgoto está ligada também a rede coletora pluvial das ruas.

A estação de tratamento de esgoto (ETE) está localizada a montante, próximo do canal do rio do Brás, no bairro Cachoeira do Bom Jesus e é chamada de ETE do Rio do Brás. Está situada em terrenos de planície flúvio- lacustre, com baixas altitudes, solos arenosos e lençol freático muito próximo da superfície. Esta estação é do tipo "lodo ativado por valor de oxidação na modalidade aeração prolongada" e tinha vazão em 2016 de 156 litros por segundo, podendo chegar a ultrapassar os 250 litros por segundo na alta temporada (CASAN, 2016).

Foram identificados como problemas presentes na ETE do rio do Brás: a chegada de muita gordura (falta de caixa de gordura nos imóveis), grande quantidade de areia e grande quantidade de água em função da ligação da água pluvial na rede de esgoto. Além disso, foi observado significativo volume de resíduos sólidos (lixo) que também chega na estação com o esgoto. Tudo isso atrapalha o funcionamento da ETE.

Dos sete casos de poluição mais significativos encontrados no período entre 2000 e 2016, todos estão relacionados com chuvas intensas que aumentam a vazão do rio do Brás e, por sua, vez provocam o rompimento de sua foz na praia. Diferentes causas para a poluição do rio foram elencadas, tais como: a chegada do escoamento pluvial da avenida principal no rio do Brás, o qual continha esgotos por causa da ligação clandestina de moradores (episódios dos anos de 2000, 2011 e do início de 2015), extravasamento da estação elevatória que fica junto do canal do rio do Brás porque chegou muita água da chuva junto com o esgoto, além de aumento da demanda propriamente dita dos esgotos, pois a estação não tem mais capacidade de lidar com esse aumento (eventos de 2006, 2010 e verão 2015/2016).

No episódio do verão de 2015/2016, as chuvas foram acompanhadas de rajadas de vento que comprometeram o fornecimento de energia elétrica da estação elevatória do rio do Brás. Desta forma, os esgotos que chegaram nela foram despejados diretamente no leito do rio segundo relatos de moradores e confirmação do técnico da CASAN. Este técnico também colocou que a estação elevatória foi objeto de vandalismo em outra oportunidade, o que prejudicou o seu funcionamento. Neste evento de 2015/2016 foram registrados cerca de mil e duzentos casos de virose, na Unidade de Pronto-Atendimento (UPA) de Canasvieiras (VARGAS, 2015). Apesar do número significativo de casos de viroses, este apenas representa os atendimentos na rede pública de saúde.

A poluição da praia no início da temporada de verão de 2016 causou grande repercussão entre os turistas, devido aos problemas de saúde enfrentados por quem se ariscava a entrar no mar ou até ficar na areia. Os problemas de saúde causaram um grande número de cancelamento de reservas no setor hoteleiro da 
região, e muitos turistas anteciparam o retorno de suas férias, com medo do surto de virose causada pela água e areia poluídas da praia. Esta conjuntura causou significativo prejuízo econômico na região.

\section{Conclusão}

As chuvas intensas são o fator deflagrador dos casos de poluição da praia de Canasvieiras, contudo, o grande problema é a carga de poluentes que o rio do Brás contém. Esta poluição do rio é causada pela chegada de esgotos clandestinos na rede pluvial que deságua no rio e por problemas de mau funcionamento da estação elevatória do "Sistema do rio do Brás" que fica as margens do rio. Também a falta de capacidade do sistema como um todo frente ao aumento da demanda tanto da população residente quanto da população flutuante de temporada são causas que contribuem para a poluição do rio e da praia.

Em 2016 e início de 2017, foram realizados investimentos por parte da CASAN para aumentar a capacidade do sistema, especialmente da estação elevatória junto ao rio do Brás e da ETE. Contudo, isso não será suficiente para resolver o problema, pois ainda é necessário que os moradores da região efetivamente façam a ligação de seus esgotos na rede coletora, tenham caixas de gordura, não joguem as águas pluviais do seu imóvel na rede de esgoto, não coloquem resíduos sólidos junto com os esgotos. É preciso um trabalho permanente de conscientização da população da região atendida pelo sistema de coleta e tratamento de esgoto do rio do Brás, acompanhado de fiscalização contínua dos órgãos públicos responsáveis.

\section{REFERÊNCIAS}

\section{CASAN (COMPANHIA CATARINENSE DE ÁGUAS E SANEAMENTO). CASAN apresenta 33 ações para} Sistemas de Esgoto de Florianópolis. Florianópolis 25 de janeiro de 2016. Disponível em: http://www.casan.com.br/noticia/index/url/casan-apresenta-33-acoes-para-sistemas-de-esgoto-de-florianopolis\#0 Acesso em novembro de 2016

GONÇALVES, G. Rio do Brás: O eterno problema de Canasvieiras. Folha do Norte da Ilha, Florianópolis, 19 jan. 2016. Cidades. Disponível em http://folhanorte.com.br/2016/01/19/rio-do-bras-o-eterno-problema-de-canasvieiras/. Acesso em março de 2016.

VARGAS, D. Número de casos de virose deixa Florianópolis em alerta. Diário Catarinense. Florianópolis 09 de janeiro de 2016. Disponível em: http://dc.clicrbs.com.br/sc/noticias/noticia/2016/01/numero-de-casos-de-virosedeixa-florianopolis-em-alerta-4947957.html Acesso em outubro de 2016. 